\title{
A Nationwide Survey on the Effectiveness of Training on Endoscope Reprocessing Within the National Cancer Screening Program
}

Hye Young Shin

National Cancer Center

Da Hun Jang

National Cancer Center

Jae Kwan Jun ( $\sim$ jkjun@ncc.re.kr)

National Cancer Control Institute, National Cancer Center, Goyang 10408, Republic of Korea;

https://orcid.org/0000-0003-1647-0675

Research article

Keywords: Endoscopy, Training, Disinfection, Quality control

Posted Date: September 8th, 2020

DOI: https://doi.org/10.21203/rs.3.rs-57230/v1

License: (c) (i) This work is licensed under a Creative Commons Attribution 4.0 International License. Read Full License 


\section{Abstract}

Background: Training on endoscope reprocessing has been annually implemented for health practitioners working in endoscopy units of hospitals performing national gastric or colorectal cancer screening across the country, as part of the endoscopy quality improvement project. This study aimed to identify the effectiveness of endoscope reprocessing training.

Methods: In this cross-sectional study, education on endoscope reprocessing was implemented 18 times across the country, from June 2019 to November 2019. A total of 1,186 participants were included and 1,132 of them answered the survey questionnaire (response rate, $95.4 \%$ ).

Results: Of the study participants, $45.8 \%$ had previous experience in training on endoscope reprocessing, and $87.6 \%$ of them have adhered to the endoscope reprocessing guidelines. Experience of participation in endoscope reprocessing training was significantly associated with practical adherence to endoscope reprocessing guidelines (aOR, 6.55; 95\% Cl, 3.93 to 10.91). The satisfaction with and need for endoscope reprocessing training were $92.7 \%$ and $95.7 \%$, respectively. The level of knowledge and intention to adhere to endoscope reprocessing guidelines were both high (4.65 [1-5]).

Conclusions: Training on endoscope reprocessing currently provided at the national level could be effective for obtaining quality control for endoscopy. However, completion of the training by actual practitioners in charge of endoscope reprocessing within the national cancer screening system remains low; thus, strategies for more aggressive training participation for them should be developed at a national level.

\section{Background}

Diagnosis and treatment for gastrointestinal diseases are mainly confirmed through gastrointestinal endoscopy, whereby the patient's gastrointestinal mucous membranes are examined. Several microorganisms and viruses existing in secretions, saliva, or blood of the gastrointestinal mucosa are transmitted from patient to patient through endoscopic procedures [1, 2]. In particular, exogenous bacteria such as Pseudomonasaeruginosa, Salmonella spp, Serratia spp, Clostridiumdifficile, and H. pylori and viruses such as HIV, hepatitis B, and hepatitis $C$ are frequently transmitted $[1,3,4]$. However, episodes of endoscopy-related infections are not reported accurately since infections might only manifest as serious diseases after months or years and infection surveillance for endoscopy facilities is insufficient $[2,5]$. Thus, only some cases have been reported. Langlay et al. [6] have collected and presented several cases of endoscopy-related infections reported through newspapers, magazines, press releases, government agencies' websites, and reports in North America, from 2005 to 2012.

Endoscope reprocessing is a crucial step in preventing infection transmission $[4,6,7]$. Importantly, proper endoscope reprocessing has been reported to prevent over $90 \%$ of endoscopy-related infections $[8,9]$. Guidelines for endoscope reprocessing has been continuously developed and revised since 1988 [5]. In Korea, the Korean Society of Gastrointestinal Endoscopy (KSGE) presented the first endoscope reprocessing guidelines in 1995 and recently revised and published the third endoscope reprocessing guideline in 2015 [10]. Additionally, the National Endoscopy Quality Improvement Program included endoscope reprocessing to enhance the endoscopy unit quality by performing national cancer screening, which was introduced and revised in 2009 [10, 11]; the Accredited Endoscopy Unit Program has recently been updated [12]. 
As part of the National Cancer Screening Program (NCSP), free screening endoscopy has been implemented for gastric and colorectal cancers in Korea since 2004 [13]. Accordingly, the National Cancer Center (NCC) has provided endoscope reprocessing training, targeting endoscopy staff members of regional hospitals performing national gastric and colorectal cancer screening annually throughout the country since 2012 to ensure quality control of the endoscopy units.

Herein, we evaluated the effectiveness of nationwide training for endoscope reprocessing based on adherence to the reprocessing guidelines in practice, satisfaction with and need for training, and knowledge and intention to adhere to the reprocessing guidelines under the hypothesis that the training is more beneficial to quality control of the endoscopy units.

\section{Methods}

\section{Study design and participants}

This was a descriptive cross-sectional study. The study participants were 1,132 endoscopy staff members, all in charge of endoscope reprocessing in clinics and hospitals designated as gastric or/and colorectal cancer screening units by the National Health Insurance Service across the country. Endoscope reprocessing training was organized by the NCC and has been performed annually since 2012 . Here, we used the data from training conducted from June 2019 to November 2019. During that period, a total of 18 training sessions were provided according to the administrative divisions of the Republic of Korea. There were 37 to 108 attendants per training session, and up to 2 endoscopy staff members at one hospital or clinic could attend. Training sessions consisted of lectures and practices on endoscope reprocessing, which took about 3 hours. Training was undertaken by a professor of the KSGE and a nurse of the Korean Society of Gastrointestinal Endoscopy Nurses and Associates. The total number of attendants was 1,186; among them, 1,132 answered the survey after the training (response rate, $95.4 \%$ ). This study was approved by the National Cancer Center Institutional Review Board in Korea (approval number: NCC2020-0045).

\section{Study instruments}

\section{Participants' general characteristics}

Socio-demographic characteristics considered were sex, age, and occupation. Work-related hospital characteristics were hospital type and cancer screening type performing in hospital.

\section{Endoscope reprocessing practice based on the guidelines and evaluation of endoscope reprocessing training}

Endoscope reprocessing practice consisted of 2 questions about whether endoscope reprocessing training has been attended in the past and whether learnt endoscopy reprocessing based on the guideline has been practiced or not. Regarding evaluation of the present endoscope reprocessing training, we developed several items including satisfaction with and need for reprocessing training, and knowledge and intention to adhere to the reprocessing guidelines. Items for satisfaction and need were surveyed using the following question, "How satisfied are you with the endoscope reprocessing training?" and "How much did you feel the need to undergo an endoscope reprocessing training?" Satisfaction was measured using a 5-point Likert scale (1, strongly satisfied; 2 , satisfied; 3 , uncertain; 4, dissatisfied; 5, strongly dissatisfied). Satisfaction was defined with a Likert score of 1-2 points; dissatisfaction was defined with a Likert score of 3-5 points. Need was determined similarly to 
satisfaction. Knowledge and intention were determined with each question, "I understood the process of endoscope reprocessing", and "I intend to work in the actual workplace according to the reprocessing guidelines learnt", respectively. These items were answered on a 5-point Likert scale ranging from "strongly agree" to "strongly disagree." Responses were calculated by inverse coding, where the highest score represented higher knowledge and intentions.

\section{Statistical analysis}

Collected data were analyzed using SAS software (ver. 9.4; SAS Institute, Cary, NC, USA). We performed descriptive statistics using frequencies and percentages or means and standard deviations. Additionally, multiple logistic regression analysis was conducted to identify the factors affecting practical adherence to endoscope reprocessing guidelines.

\section{Results}

A total of 1,132 participants were included in the analysis. Among them, $97.8 \%$ were women, $2.2 \%$ were men, and $52.1 \%$ were aged over 40 years (Table 1$)$. The occupations included auxiliary nurses $(70.2 \%)$, nurses (25.2\%), and doctor (1.1\%). Participants mostly worked in clinics (64.0\%), followed by hospitals (21.5\%) and general hospitals (14.6\%). Regarding participation in endoscope reprocessing education, $45.8 \%$ had previous educational experience, while $54.2 \%$ had no experience; $96.1 \%$ of those who participated in the educational process (and $80.3 \%$ of those who did not participate in it) answered that they have conducted endoscope reprocessing according to the guidelines (Table 2). Satisfaction and needs with endoscope reprocessing education were $92.7 \%$ and $95.7 \%$, respectively. The score for both knowledge and high intention to perform endoscope reprocessing in accordance with the guidelines was 4.65 [possible range, 1-5] (Table 2).

Factors associated with adherence to the endoscope reprocessing guidelines are shown in Table 3. Among participants who adhered to the guidelines, $50.74 \%$ had participated in reprocessing training before, while, among participants who did not adhere to that, $14.6 \%$ participated in training. Experience of participation in endoscope reprocessing training was significantly associated with practical adherence to the endoscope reprocessing guidelines (aOR, 6.55; 95\% Cl, 3.93 to 10.91).

\section{Discussion}

The purpose of this study was to evaluate the effectiveness of endoscope reprocessing training provided to hospitals conducting national gastric or/and colorectal cancer screening. Experience of participation in endoscope reprocessing training in the past was a significant factor associated with adhering to reprocessing guidelines in practice. After the training, most of the participants showed high satisfaction with and need for training and high level of knowledge and intention to adhere to the reprocessing guidelines at their workplace.

Practical adherence to endoscope reprocessing guidelines among those who had experience in reprocessing training was significantly higher, compared with that among those who did not have the training experience in our study. Moreover, after training on endoscope reprocessing, the majority of study participants showed high level of knowledge (4.65 [1-5]) and intention of adherence (4.65 [1-5]) to reprocessing guidelines. These similar endoscope reprocessing-relayed beneficial outcomes have been reported in studies of other countries. AbdElhamid et al. (2016) have reported that nursing staff adherence to infection control principles for endoscope 
reprocessing procedures was 83.3\% after training, which significantly increased from 10.0\% before training [14]. Additionally, decreasing incidence of microbial infection transmission in Yemen and Egypt, as well as increasing knowledge and skills for infection control in endoscopy units was significant after receiving the infection control program $[15,16]$. According to the Korean survey of nurses and nursing auxiliaries working in endoscopy units at secondary and tertiary hospitals, $98.0 \%$ of participants attended in endoscope reprocessing training at least once, and $98.9 \%$ adhered to the endoscope reprocessing guidelines [17]. After all, adherence to the reprocessing guidelines might be highly associated with reprocessing training. Unfortunately, however, $54.2 \%$ of participants in our study did not previously participate in the educational process, only $80.3 \%$ of them responded that they worked in accordance with the reprocessing guidelines. Moreover, previous studies conducting in NSCP have shown that $15-17 \%$ of physicians did not follow the reprocessing guidelines [18], and only $53.3 \%$ of nursing staff completed the reprocessing training program [11]. Therefore, based on the above findings, we argue that endoscope reprocessing training should be conducted more actively to achieve better performance of endoscopy infection control throughout the country.

The majority of the study participants showed high satisfaction with and need for endoscope reprocessing training. The study conducting worldwide survey of 39 countries on endoscopic reprocessing practice reported that $50.0 \%$ of respondents expressed the requirement for reprocessing training for patient safety [19]. However, need for training may vary depending on the type of medical institution. A survey targeting the KSGE ethics and quality control committee (mainly composed of endoscopy specialists of a large medical institute) reported that approximately $80 \%$ of respondents answered that quality control of endoscope reprocessing has been improved, $60 \%$ answered that they had designed their own quality control training programs for endoscopy units, and $31 \%$ answered that they had established their own reprocessing training guidelines [10]. Contrary to the above mentioned results, our participants mostly worked in relatively small medical institutions, such as clinics or hospitals; only $45.8 \%$ had previous experience in training participation. Considering that a large of number of screening endoscopies within the NCSP has also been performed in clinics or hospitals (where resources and finances are not limited), the high level of need for training should be addressed with appropriate training activities to sufficiently meet the national system requirements.

Our study has several limitations. Firstly, we evaluated the participants' practical adherence to the endoscope reprocessing guidelines through a self-report questionnaire instead of direct workplace surveillance; thus, our results might have been overestimated. However, since the reprocessing training was conducted across the country, it was difficult to evaluate the actual adherence to the reprocessing guidelines among endoscopy units' staff. Also, detail evaluation of entire endoscope reprocessing steps from transport in a sealed container to storage $[17,20]$ was not conducted; thus, the result of knowledge level on reprocessing guidelines might not be accurate. Nevertheless, the results of this study might represent the effectiveness of endoscope reprocessing training, since training was provided to actual endoscopy practitioners working in endoscopy units. Furthermore, our findings composed the first evaluation of the nationally implemented training, identifying the achievements and need for continued training.

\section{Conclusions}

In conclusion, training for endoscope reprocessing currently provided at a national level could be effective to obtain quality improvement for endoscope screening by increasing practical adherence and knowledge of the endoscope reprocessing guidelines. However, since current completion of endoscope reprocessing training

Page 5/11 
among actual endoscopy practitioners in NCSP is low, strategies for more aggressive training participation and dissemination should be developed.

\section{List Of Abbreviations}

KSGE: Korean Society of Gastrointestinal Endoscopy; NCSP: National Cancer Screening Program; NCC: National Cancer Center

\section{Declarations}

\section{Ethics approval and consent to participate}

This study was approved by the National Cancer Center Institutional Review Board in Korea (approval number: NCC2020-0045). The IRB waived the requirement for the investigator to obtain a signed consent form for study participants because the research no more than minimal risk and the questionnaire was completed only by those who agreed to fill it out.

\section{Consent for publication}

Not applicable

\section{Availability of data and materials}

The datasets are available from the corresponding author on reasonable request.

\section{Competing interests}

The authors declare that they have no conflict of interest.

\section{Funding}

This study was supported by a Grant-in Aid for Cancer Research and Control from the National Cancer Center of Korea (Grant No. 1910233-1). This funding source had no role in the study design, study setting, analysis, or writing of the manuscript.

\section{Authors' contributions}

Data analysis and interpretation: H.Y.S. Data acquisition: D.H.J. Writing of the manuscript: H.Y.S. Study concept and design, critical revision of the manuscript for important intellectual content, obtaining of fund, and study supervision: J.K.J. All authors have read and approved the manuscript.

\section{Acknowledgments}

We deeply appreciate all members of the Korean Society of Gastrointestinal Endoscopy and the Korean Society of Gastrointestinal Endoscopy Nurses and Associates.

\section{References}


1. Weber DJ, Rutala WA. Assessing the risk of disease transmission to patients when there is a failure to follow recommended disinfection and sterilization guidelines. Am J Infect Control. 2013;41:67-71.

2. Petersen BT. Duodenoscope reprocessing: risk and options coming into view. Gastrointest Endosc. 2015;82:484-7.

3. Kovaleva J, Peters FT, van der Mei HC, Degener JE. Transmission of infection by flexible gastrointestinal endoscopy and bronchoscopy. Clin Microbiol Rev. 2013; 26:231-54.

4. Cristina ML, Sartini M, Schinca E, Ottria G, Dupont C, Bova P, et al. Is Post-Reprocessing Microbiological Surveillance of Duodenoscopes Effective in Reducing the Potential Risk in Transmitting Pathogens? Int J Environ Res Public Health. 2020;17(1):140.

5. Srinivasan A. Epidemiology and prevention of infections related to endoscopy. Curr Infect Dis Rep. 2003;5:467-72.

6. Langlay AMD, Ofstead CL, Mueller NJ, Tosh PK, Baron TH, Wetzler HP. Reported gastrointestinal endoscope reprocessing lapses: the tip of the iceberg. Am J Infect Control. 2013; 41:1188-94.

7. Zhang X, Kong J, Tang P, Wang S, Hyder Q, Sun G, et al. Current status of cleaning and disinfection for gastrointestinal endoscopy in China: a survey of 122 endoscopy units. Dig Liver Dis. 2011;43:305-8.

8. Seoane-Vazquez E, Rodriguez-Monguio R, Visaria J, Carlson A. Endoscopy-related infections and toxic reactions: an international comparison. Endoscopy. 2007;39:742-778.

9. Marion K, Freney J, James G, Bergeron E, Renaud F, Costerton JW. Using an efficient biofilm detaching agent: an essential step for the improvement of endoscope reprocessing protocols. J Hosp Infect. 2006;64:136-42.

10. Cho YK, Moon JS, Han DS, Lee YC, Kim Y, Park BY, et al. Feedback survey of the effect, burden, and cost of the national endoscopic quality assessment program during the past 5 years in Korea. Clin Endosc. 2016;49:542.

11. Min JK, Cha JM, Kwak MS, Yoon JY, Jung Y, Shin JE, et al. Quality indicators and outcome measures of endoscopy in the national cancer screening program. Yonsei Med J. 2019; 60:1054-60.

12. Shin JE, Jung Y, Lee JH, Son BK, Jang J-Y, Kim H-K, et al. Updates on the disinfection and infection control process of the accredited endoscopy unit. Clin Endosc. 2019;52:443-50.

13. Suh M, Song S, Cho HN, Park B, Jun JK, Choi E, et al. Trends in participation rates for the national cancer screening program in Korea, 2002-2012. Cancer Res Treat. 2017;49:798-806.

14. Abd-Elhamid A, El-khashab M, Taha N, Saleh M. Impact of training education program on improving of nurses' performance regarding infection control in endoscopy unit. AJIED. 2016;6:16-28.

15. Moqbel AA, Shebl AM, Soliman HM. Effectiveness of planned health education program on nurses' knowledge and practice for preventing infection in gastrointestinal endoscopy units at major hospitals in Yemen. J Nurs Health Sci. 2015:2320-1959.

16. Ali ZH, Taha NM. Effect of infection control training program on nurse's performance and microbial results on GIT endoscopes. ZNJ. 2014;10:163-80.

17. Park JB, Yang JN, Lim YJ, Koo JS, Jang JY, Park SH, et al. Survey of endoscope reprocessing in Korea. Clin Endosc. 2015;48:39-47.

18. Cha JM, Moon JS, Chung I-K, Kim J-O, Im JP, Cho YK, et al. National endoscopy quality improvement program remains suboptimal in Korea. Gut Liver. 2016; 10:699-705. 
19. Kenters N, Tartari E, Hopman J, El-Sokkary RH, Nagao M, Marimuthu K, et al. Worldwide practices on flexible endoscope reprocessing. Antimicrob Resist Infect Control. 2018;7:153.

20. Oh TH, Han ST, Hong KI, Jeong EH, Lee H, Yun JW, et al. Guidelines of cleaning and disinfection in gastrointestinal endoscope for clinicians. J Korean Med Assoc. 2018;61:130-8.

\section{Tables}

Table 1. General characteristics of the study participants $(N=1,132)$.

\begin{tabular}{|c|c|c|}
\hline Characteristics & $\mathrm{n}$ & $(\%)$ \\
\hline \multicolumn{3}{|l|}{ Sex } \\
\hline Male & 25 & $(2.2)$ \\
\hline Female & 1090 & $(97.8)$ \\
\hline \multicolumn{3}{|l|}{ Age, years } \\
\hline $20-29$ & 186 & $(16.7)$ \\
\hline $30-39$ & 349 & $(31.3)$ \\
\hline$\geq 40$ & 581 & $(52.1)$ \\
\hline \multicolumn{3}{|l|}{ Occupation } \\
\hline Doctor & 12 & $(1.1)$ \\
\hline Nurse & 280 & $(25.2)$ \\
\hline Auxiliary nurse & 781 & $(70.2)$ \\
\hline Others & 40 & $(3.6)$ \\
\hline \multicolumn{3}{|l|}{ Hospital type } \\
\hline General hospital & 162 & $(14.6)$ \\
\hline Hospital & 239 & $(21.5)$ \\
\hline Clinic & 712 & $(64.0)$ \\
\hline \multicolumn{3}{|l|}{ Cancer screening type performing in hospital } \\
\hline Gastric or colorectal cancer screening & 122 & $(11.1)$ \\
\hline Gastric and colorectal cancer screening & 979 & $(88.9)$ \\
\hline
\end{tabular}

Table 2. Endoscope reprocessing practice and effectiveness of endoscope reprocessing education $(\mathbb{N}=1,132)$. 


\begin{tabular}{|c|c|c|}
\hline Items & $\mathbf{n}$ & $(\%)$ \\
\hline \multicolumn{3}{|l|}{ ENDOSCOPIC REPROCESSING PRACTICE } \\
\hline \multicolumn{3}{|c|}{ Participation in endoscope reprocessing education in the past } \\
\hline No & 612 & $(54.2)$ \\
\hline Yes & 517 & $(45.8)$ \\
\hline \multicolumn{3}{|l|}{ Adherence to endoscope reprocessing guidelines } \\
\hline No & 137 & $(12.4)$ \\
\hline Yes & 965 & $(87.6)$ \\
\hline \multicolumn{3}{|c|}{ Adherence (YES: respondents of education participation in the past) } \\
\hline No & 20 & $(3.9)$ \\
\hline Yes & 489 & $(96.1)$ \\
\hline \multicolumn{3}{|c|}{ Adherence (NO: respondents of education participation in the pasts) } \\
\hline No & 117 & $(19.7)$ \\
\hline Yes & 476 & $(80.3)$ \\
\hline \multicolumn{3}{|l|}{ Disinfectants } \\
\hline Glutaraldehyde (Cidex®, Wydex $\left.{ }^{\circledR}\right)$ & 143 & $(13.0)$ \\
\hline Ortho-phthalaldehyde (Cidex-OPA®) & 488 & $(44.5)$ \\
\hline Peracetic acid/hydrogen peroxide & 342 & $(31.2)$ \\
\hline Others & 124 & $(11.3)$ \\
\hline \multicolumn{3}{|c|}{ EFFECTIVENESS OF ENDOSCOPE REPROCESSING EDUCATION } \\
\hline \multicolumn{3}{|l|}{ Satisfaction with endoscopic reprocessing education } \\
\hline No & 81 & $(7.3)$ \\
\hline Yes & 1030 & $(92.7)$ \\
\hline $\begin{array}{l}\text { Knowledge on appropriate endoscope reprocessing } \\
\text { (mean, SD), (range, 1-5) }\end{array}$ & 4.65 & $(0.50)$ \\
\hline $\begin{array}{l}\text { Intention on appropriate endoscope reprocessing } \\
\text { (mean, SD), (range, 1-5) }\end{array}$ & 4.65 & $(0.52)$ \\
\hline \multicolumn{3}{|l|}{ Need for endoscopic reprocessing education } \\
\hline No & 48 & $(4.3)$ \\
\hline Yes & 1063 & $(95.7)$ \\
\hline
\end{tabular}

Table 3. Predictors associated with practical adherence to endoscopic reprocessing guideline $(N=1,132)$. 


\begin{tabular}{|c|c|c|c|c|c|c|c|c|c|}
\hline \multirow[t]{3}{*}{ Items } & \multicolumn{9}{|c|}{ Guideline adherence } \\
\hline & \multicolumn{2}{|l|}{ Yes } & \multicolumn{2}{|l|}{ No } & \multirow{2}{*}{$\begin{array}{l}\mathrm{p}- \\
\text { value }\end{array}$} & \multicolumn{2}{|c|}{ Yes vs. No } & \multicolumn{2}{|c|}{ Yes vs. No } \\
\hline & $\mathrm{n}$ & $(\%)$ & $\mathrm{n}$ & $(\%)$ & & $\mathrm{cOR}$ & $(95 \% \mathrm{Cl})$ & $\mathrm{aOR}$ & $(95 \% \mathrm{Cl})$ \\
\hline \multicolumn{10}{|c|}{ Participation in endoscope reprocessing education in the past } \\
\hline No & 476 & (49.3) & 117 & (85.4) & \multirow[t]{2}{*}{$<.001$} & 1.00 & (reference) & 1.00 & (reference) \\
\hline Yes & 489 & $(50.7)$ & 20 & $(14.6)$ & & 6.01 & $\begin{array}{l}(3.68- \\
9.82)\end{array}$ & 6.55 & $\begin{array}{l}(3.93- \\
10.91)\end{array}$ \\
\hline \multicolumn{10}{|l|}{ Sex } \\
\hline Male & 20 & $(2.1)$ & 5 & (3.7) & \multirow[t]{2}{*}{0.222} & 1.00 & (reference) & 1.00 & (reference) \\
\hline Female & 932 & $(97.9)$ & 129 & $(96.3)$ & & 1.80 & $\begin{array}{l}(0.66- \\
4.88)\end{array}$ & 0.96 & $\begin{array}{l}(0.22- \\
4.19)\end{array}$ \\
\hline \multicolumn{10}{|l|}{ Age (years) } \\
\hline $20-29$ & 164 & $(17.2)$ & 18 & $(13.4)$ & \multirow[t]{3}{*}{0.544} & 1.00 & (reference) & 1.00 & (reference) \\
\hline $30-39$ & 296 & $(31.1)$ & 44 & $(32.8)$ & & 0.74 & $\begin{array}{l}(0.41- \\
1.32)\end{array}$ & 0.83 & $\begin{array}{l}(0.45- \\
1.53)\end{array}$ \\
\hline$\geq 40$ & 492 & $(51.7)$ & 72 & $(53.7)$ & & 0.76 & $\begin{array}{l}(0.44- \\
1.30)\end{array}$ & 0.72 & $\begin{array}{l}(0.40- \\
1.28)\end{array}$ \\
\hline \multicolumn{10}{|l|}{ Occupation } \\
\hline Doctor & 7 & $(0.7)$ & 4 & (3.0) & \multirow[t]{3}{*}{0.038} & 1.00 & (reference) & 1.00 & (reference) \\
\hline Nurse & 237 & $(25.0)$ & 37 & $(27.6)$ & & 3.66 & $\begin{array}{l}(1.02- \\
13.12)\end{array}$ & 4.60 & $\begin{array}{l}(0.72- \\
29.49)\end{array}$ \\
\hline $\begin{array}{l}\text { Auxiliary } \\
\text { nurse \& } \\
\text { others }\end{array}$ & 705 & $(74.3)$ & 93 & $(69.4)$ & & 4.33 & $\begin{array}{l}(1.24- \\
15.08)\end{array}$ & 7.14 & $\begin{array}{l}(1.15- \\
44.38)\end{array}$ \\
\hline \multicolumn{10}{|l|}{$\begin{array}{l}\text { Hospital } \\
\text { type }\end{array}$} \\
\hline $\begin{array}{l}\text { General } \\
\text { hospital }\end{array}$ & 141 & $(14.8)$ & 13 & $(9.8)$ & \multirow[t]{3}{*}{0.173} & 1.00 & (reference) & 1.00 & (reference) \\
\hline Hospital & 195 & (20.5) & 34 & (25.6) & & 0.53 & $\begin{array}{l}(0.27- \\
1.03)\end{array}$ & 0.46 & $\begin{array}{l}(0.23- \\
0.94)\end{array}$ \\
\hline Clinic & 614 & $(64.6)$ & 86 & $(64.7)$ & & 0.66 & $\begin{array}{l}(0.36- \\
1.21)\end{array}$ & 0.65 & $\begin{array}{l}(0.33- \\
1.27)\end{array}$ \\
\hline \multicolumn{10}{|c|}{ Cancer screening type performing in hospital } \\
\hline $\begin{array}{l}\text { Gastric or } \\
\text { colorectal } \\
\text { cancers }\end{array}$ & 92 & $(9.8)$ & 25 & $(18.7)$ & \multirow[t]{2}{*}{0.004} & 1.00 & (reference) & 1.00 & (reference) \\
\hline $\begin{array}{l}\text { Gastric and } \\
\text { colorectal } \\
\text { cancers }\end{array}$ & 847 & $(90.2)$ & 109 & (81.3) & & 2.15 & $\begin{array}{l}(1.32- \\
3.49)\end{array}$ & 109 & $\begin{array}{l}(1.02- \\
2.87)\end{array}$ \\
\hline
\end{tabular}


Abbreviations: $\mathrm{COR}$, crude odds ratio; $\mathrm{aOR}$, adjusted odds ratio

\section{Supplementary Files}

This is a list of supplementary files associated with this preprint. Click to download.

- QuestionnarieBMGE20200822.docx

- STROBEchecklistcrosssectionalBMGE20200822.doc 